\title{
Impact of the Invasive Brown Marmorated Stink Bug, Halyomorpha halys (Stål), in Mid-Atlantic Tree Fruit Orchards in the United States: Case Studies of Commercial Management
}

\author{
Tracy C. Leskey, ${ }^{1}$ Brent D. Short, ${ }^{1}$ Bryan R. Butler, ${ }^{2}$ and Starker E. Wright ${ }^{1}$ \\ ${ }^{1}$ USDA-ARS, Appalachian Fruit Research Station, 2217 Wiltshire Road, Kearneysville, WV 25430-2771, USA \\ ${ }^{2}$ University of Maryland Extension, Carroll County, 700 Agriculture Center Drive, Westminster, MD 21157, USA \\ Correspondence should be addressed to Tracy C. Leskey, tracy.leskey@ars.usda.gov
}

Received 11 January 2012; Accepted 2 May 2012

Academic Editor: Jeffrey R. Aldrich

Copyright ( $) 2012$ Tracy C. Leskey et al. This is an open access article distributed under the Creative Commons Attribution License, which permits unrestricted use, distribution, and reproduction in any medium, provided the original work is properly cited.

\begin{abstract}
Four commercial orchards in the mid-Atlantic region of the United States were surveyed weekly in 2010 and 2011 for the presence of brown marmorated stink bug and the injury caused to both apple and peaches. Among tested sampling techniques, pyramid traps baited with the aggregation pheromone of Plautia stali Scott, methyl-(2E,4E,6Z)-decatrienoate, yielded the most brown marmorated stink bug adults and nymphs, followed by visual observations. Brown marmorated stink bugs began to feed on apples and peaches soon after fruit set and continued to feed on fruit throughout the growing season. Injury to apple was relatively inconsequential until after mid-June, whereas feeding on peaches resulted in immediate economic injury as the surface became distorted, dented, discolored, and the flesh beneath turned brown. Significantly more apples were injured and with greater severity in 2010 than in 2011. Likewise, percent injury on the exterior portion of each apple plot was significantly greater than injury reported from the interior in both years. Growers increased the number of insecticide applications nearly 4 -fold from 2010 to 2011. In addition to the increased number of targeted insecticide applications, growers also reduced the interval between treatments in 2011. A metric was created to compare the relative intensity of each grower's commercial management program between seasons and amongst each other.
\end{abstract}

\section{Introduction}

The brown marmorated stink bug, Halyomorpha halys (Stål), is an invasive stink bug native to Japan, Korea, China, and Taiwan [1], now well established throughout the midAtlantic region of the United States. Evidence of established populations in Switzerland [2] and Canada [3] has also been reported. Brown marmorated stink bug is an extremely polyphagous species, and a pest of many crops in Asia [4] including tree fruit, vegetables, shade trees, and leguminous crops with specific mention of apple, cherry, peach, and pear $[4,5]$. Surveys conducted in the United States identified a number of tree fruit hosts for brown marmorated stink bug including apple, plum, peach, pear, and cherry [5-7]. In 2010, populations of this invasive species increased dramatically, causing widespread injury to many crops throughout the mid-Atlantic region [8]. Tree fruit, in particular, was hit hard with some growers losing entire crops of stone fruit. Among apple growers, losses were totaled in excess of 37 million dollars in the region [9].

Within the United States, native stink bugs generally have been classified as secondary pests of tree fruit orchards and have been successfully managed with broad-spectrum insecticide applications typically directed at other key pests. However, with the passage of the Food Quality Protection Act in 1996, many broad-spectrum materials have been eliminated or severely curtailed for use through regulatory measures. Subsequently, populations of native stink bugs, long considered to be secondary pests, became more prevalent in orchard agroecosystems $[10,11]$. Furthermore, when brown marmorated stink bug populations increased dramatically, this led to devastating levels of fruit injury as 
this invasive species quickly replaced lepidopteran pests such as codling moth, Cydia pomonella L., and oriental fruit moth, Grapholita molesta (Busck), as the key pest driving management decisions in the mid-Atlantic region of the United States.

Because brown marmorated stink bug is a newly established invasive species, management programs for this pest are still being developed. In 2010, no specific management recommendations were in place and only a single laboratory study evaluating a select number of compounds against brown marmorated stink bug had been conducted [12]. Growers were forced to rely on recommendations made for native stink bugs, which did not result in satisfactory control [8]. In general, pyrethroid insecticides, considered to be effective against native stink bugs, but are a poor fit in IPM programs because of their negative impact on beneficial arthropods $[13,14]$ were applied.

Recent insecticide trials against brown marmorated stink bug have revealed that numerous pyrethroid and neonicotinoid compounds at field-labeled rates are not particularly effective, with many compounds resulting in greater than $33 \%$ of the individuals recovering from a moribund or "knockdown" state [15]. This conforms to earlier laboratory [12] and field studies [16] that documented knockdown and recovery from pyrethroids specifically. On the other hand, there are a number of materials labeled for either stone or pome fruit that resulted in substantial mortality of tested individuals. Some effective materials reported in the previous study were endosulfan, a chlorinated hydrocarbon; malathion, an organophosphate; permethrin and fenpropathrin, pyrethroids; dinotefuran, a neonicotinoid; methomyl, a carbamate [15]. Prior to the establishment of brown marmorated stink bug, growers likely would not have applied many of these materials in their management programs as they were not needed to achieve acceptable levels of control of other key pests. However, management programs have rapidly evolved to meet the challenge posed by brown marmorated stink bug.

Simultaneously, development of monitoring tools that can be used to assess the presence, abundance, and seasonal activity of this invasive species is considered paramount [8]. Stink bug species are typically monitored in cropping systems using sweep nets, beating samples, pheromone-baited traps, and/or black light traps. Among native stink bugs in tree fruit, baited yellow pyramid traps $[10,11]$ and baited mullein plants [17] were effective at monitoring native Euschistus spp. while Chinavia hilaris (Say) was monitored in vegetable and row crops using black light traps [18]. Black light traps have been evaluated for brown marmorated stink bug in Japan [19] and in New Jersey [6]. Most recently, black pyramid traps baited with the aggregation pheromone of Plautia stali Scott, methyl-(2E,4E,6Z)-decatrienoate [20], were found to be an effective means to trap brown marmorated stink bug adults and nymphs $[21,22]$. However, none of these tools have been evaluated extensively against brown marmorated stink bug in commercial tree fruit orchards.

In 2010 and 2011, we surveyed commercial fruit orchards in the mid-Atlantic to quantify the amount and severity of injury to stone and pome fruit crops. We also evaluated the efficacy of established monitoring techniques for other stink bug species to measure presence, abundance, and seasonal activity of populations of brown marmorated stink bug. Finally, we quantified the changes in management programs from 2010 to 2011 in terms of material selection, interval, and application method.

\section{Materials and Methods}

2.1. Commercial Site Selection. We attempted to evaluate the population density of brown marmorated stink bug and severity of injury to apple and peach fruit in two West Virginia and two Maryland orchards. In 2010, the project began during mid-season (July) and continued through November. Grower orchards were selected based on (1) the presence of brown marmorated stink bug infestations and (2) the availability of both apples and peaches as hosts. Specific apple and peach plots within orchards were chosen based on grower reports of stink bug injury and close proximity $(<20 \mathrm{~m})$ to wooded/wild habitats. Orchard A consisted of a 2.9 ha apple orchard ("Fuji" on M7A; Spacing: $4.9 \mathrm{~m} \times 7.3 \mathrm{~m}$ ) planted in 1995 and a 1.3 ha peach orchard ("Redhaven" on Tenn. Nat. and "Sentry" and "Bounty" on Lovell; Spacing: $4.3 \mathrm{~m} \times 7.3 \mathrm{~m}$ ) planted in 2001. Orchard B consisted of a 5.7 ha apple orchard ("Delicious" and "Golden Delicious" on M111; Spacing: $6.2 \mathrm{~m} \times 8.6 \mathrm{~m}$ ) planted in 1996 and a 5.3 ha peach orchard ("Sunbright" on Lovell; Spacing: $6.2 \mathrm{~m} \times 7.4 \mathrm{~m}$ ) planted in 1996. Orchard C consisted of 1.9 ha apple orchard ("Golden Delicious" on M111; Spacing: $4.2 \mathrm{~m} \times 7.6 \mathrm{~m}$ ) planted in 1975 and a 0.7 ha peach orchard ("Red Haven" and "Blake" on Lovell; Spacing: $4.2 \mathrm{~m} \times 7.6 \mathrm{~m}$ ) planted in 1997. Orchard D consisted of a 1.8 ha apple orchard ("Delicious" on M26, "Fuji", "Braeburn", "Mutsu", "Empire", "Jonagold" and "Magnolia Gold" on M9; Spacing: $2.7 \mathrm{~m} \times 4.0 \mathrm{~m}$ ) planted in 1992 and a 2.4 ha peach orchard (mostly "Loring", "Cresthaven", "Encore", "White Lady" and "Redhaven" on Lovell, "Beekman" on Tenn. Nat. and "John Boy" on Guardian; Spacing: $5.2 \mathrm{~m} \times 6.1 \mathrm{~m}$ ) planted in 1998 . In 2011, the same four growers' orchards were monitored and evaluated for brown marmorated stink bug presence and injury to fruit throughout the entire growing season (April-November). The only exception was at orchard C where the apple plot was 1.8 ha ("Fuji" and "York" on M111/M9 interstem; Spacing: $3.0 \mathrm{~m} \times 6.1 \mathrm{~m}$ ) planted in 2001 and the peach plot was 1.9 ha (mostly "Canadian Harmony", "Bounty", and "Blake" on Lovell; Spacing: $3.7 \mathrm{~m} \times 6.1 \mathrm{~m}$ ) planted in 2003.

2.2. Aggregate Insecticide Metric (AIM). Growers selected their own spray programs for both seasons; however, growers used more targeted treatments against brown marmorated stink bug in 2011. In order to assess the insecticide treatment programs used in 2010 and 2011, a metric (AIM) was created that would compare quantitatively the differences in material and application method for each chemical used. The AIM takes into account the lethality of the active ingredient against brown marmorated stink bug [15], the number of insect Orders listed as controlled on each product label, the proportion of chemical used by the grower versus the 
maximum allowed according to approved label directions, and the method of application (complete block or alternate row middle).

2.2.1. Material. Each material/active ingredient was compared by a series of three steps: (1) general insect toxicity,

(2) specific brown marmorated stink bug toxicity, and (3) amount of active ingredient used. First, general insect toxicity $\left(\mathrm{G}_{i}\right)$ was assessed by counting the number of insect Orders presumed (according to the specific product label) to be controlled upon use of the chemical, then dividing that number by the number of insect Orders available for control and presented as a proportion (0 to 1). The identified Orders of insects available for control were Coleoptera, Diptera, Hemiptera, Homoptera, Hymenoptera, Lepidoptera, Orthoptera, and Thysanoptera [23]. Specific brown marmorated stink bug toxicity $\left(S_{i}\right)$ was evaluated among chemicals by use of the lethality index reported in Leskey et al. [15]. This index was based on the results from laboratory tests on adult brown marmorated stink bugs exposed to high field-rate doses of various active ingredients, presented as dislodgeable, dry residues for a period of $4.5 \mathrm{~h}$. Subsequently, all test subjects were evaluated daily over a 7-d period for their condition (alive, moribund, or dead). These data comprise the lethality index, which assigned a value 0 to 100 based on the speed and efficacy at which a chemical acted against the brown marmorated stink bug; however, in this publication the lethality index was assessed from 0 to 1 to standardize with other factors in the model. Increased efficacy yielded a higher number and vice versa. In the third examination of each material, the amount of active ingredient $\left(\mathrm{A}_{i}\right)$ used in each application was calculated as a proportion ( 0 to 1 ) of the amount of material the label permits per application. Thus the amount of material used was divided by the maximum amount that could have been used.

2.2.2. Application Method $\left(M_{i}\right)$. All growers used one of two methods for applying pesticides to their fruit trees: complete block or alternate row middle sprays [24]. In the complete block spray, chemicals were applied to every tree from every drive row within a plot. In the alternate row middle spray, chemicals were applied to one half of every tree via the use of every other drive row within a plot. A complete block spray was assigned a value of 1 whereas an alternate row middle spray was assigned a value of 0.5 .

2.2.3. AIM Formula. The AIM value for each insecticide application was calculated by multiplying each factor:

$$
\mathrm{G}_{i} \times \mathrm{S}_{i} \times \mathrm{A}_{i} \times \mathrm{M}_{i}
$$

For each grower by year and fruit species, we calculated the mean AIM and total AIM. Given that grower management programs were not limited to control of brown marmorated stink bug, statistical comparisons of the mean interval between applications and the mean AIM score was computed for all growers combined. These means were compared using Student's $t$-test $(P<0.05)$.
2.3. Sampling/Monitoring. From 12 May to 20 October 2011, two commercial orchards (A \& C) were monitored weekly for brown marmorated stink bug presence by the use of three sampling techniques: sweep net, limb jarring, and visual surveying. Each sampling technique was performed in both apple [12 May to 6 October (orchard A) and from 12 May to 20 October(orchard C)] and peach (12 May to 7 July) plots at each orchard.

2.3.1. Sweep Net Samples. Three areas were sampled at the border of the wooded/wild habitat proximal to each orchard plot and spaced equidistant to span the length of the plot. Fifty sweeps of the ground flora, consisting of a back-andforth motion, were performed weekly in each area covering approximately $5 \mathrm{~m}^{2}$. The number of nymphs and adults collected were taken to the laboratory and counted.

2.3.2. Limb Jarring Samples. Eight apple and peach trees were selected from the perimeter row of each plot that bordered a wooded/wild habitat and were then revisited each week for subsequent samples. Two limbs on opposing sides were sampled by striking each limb three times onto a $1 \mathrm{~m}^{2}$ canvas beating sheet (BioQuip, Rancho Dominguez, CA) to collect dislodged insects. All nymphs and adults on the sheet were counted and totaled for each tree.

2.3.3. Visual Surveys. Eight additional apple and peach trees were selected from the perimeter row of each plot that bordered a wooded/wild habitat and were then revisited each week for subsequent samples. Each sample consisted of a 3-min visual inspection of all parts of the tree. All brown marmorated stink bug eggs (hatched and unhatched), nymphs, and adults were counted and any hatched eggs discovered were removed from the tree.

2.3.4. Trapping. On 4 August 2010, three black pyramid traps [21] were deployed in the perimeter tree row of apple plots at each commercial orchard. All traps were placed along the perimeter that bordered a wooded/wild habitat. In 2010, traps were baited with $50 \mathrm{mg}$ of methyl-(2E,4E,6Z)decatrienoate (ChemTica Intl., Atlanta, GA), an aggregation pheromone of Plautia stali Scott [20] and a known crossattractant to the brown marmorated stink bug [22]. Traps were also provisioned with an insecticidal strip containing 10\% 2,2-dichlorovinyl dimethyl phosphate (Vaportape II, Hercon, Emigsville, PA) to inhibit stink bug escape from the trap. The chemical attractant and insecticidal strip were replaced at 4 -wk intervals. Brown marmorated stink bug adults captured in traps were sexed, and nymphs were separated by instar and then removed from the trap weekly until 10 November. In 2011, a prototype trap developed by AgBio (Westminster, CO), patterned after the 2010 trap, was used in both apple and peach blocks at the four commercial orchards described previously. The pyramid base was constructed from 2 sheets of laminated plywood joined together with glue and staples. The trap was painted with flat black exterior latex paint and was $1.1 \mathrm{~m}$ tall $\times 0.5 \mathrm{~m}$ wide at base $\times 0.64 \mathrm{~cm}$ thick (Figure 1(a)). A 1.9 L plastic jar 


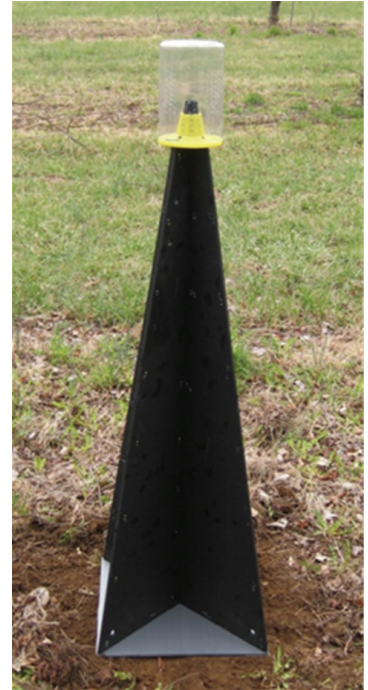

(a)

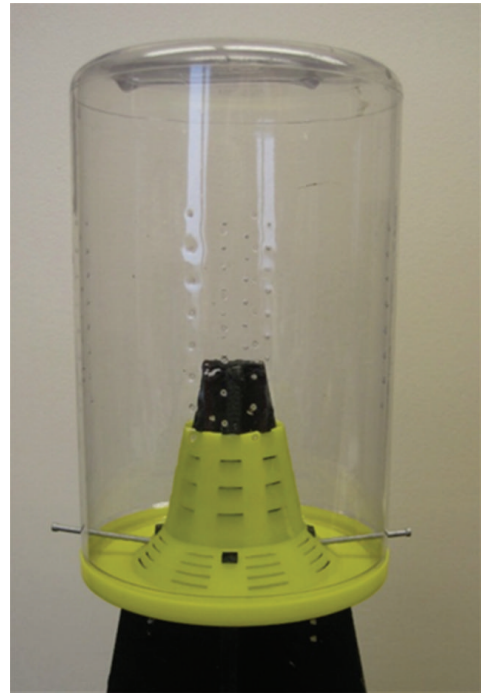

(b)

Figure 1: (a) Photo of pyramid trap and (b) jar top used in commercial orchards in 2011.

top was fixed atop a yellow plastic funnel with an opening of approximately $2.5 \mathrm{~cm}$, which served as the entry point at the base of the jar. The funnel was not permanently attached to the jar top because its contents were accessed by separation of the jar top from the funnel. A hole was drilled into each edge of the pyramid trap so that the funnel and jar could be held in place at the top of the pyramid by four $5.1 \mathrm{~cm}, 6$-penny nails pushed into the sides of the trap. The four sides of the jar top contained 23 holes, $1 \mathrm{~mm}$ in diameter, spaced $1 \mathrm{~cm}$ apart over $14 \mathrm{sq} \cdot \mathrm{cm}$ (Figure 1(b)). The same lure and insecticidal strips were used as in 2010, except the load was increased to $66 \mathrm{mg}$. Placement of traps and sampling protocols were similar to those used in 2010, with only sampling period duration differing. Traps were sampled weekly from 8 April (Orchards A-C) and 15 April (Orchard D) through 18 November. The number of brown marmorated stink bugs captured per week from 4 August to 12 November was compared between years with Student's $t$ test. The change in the ratio of adults: nymphs captured in apples in 2010 at each orchard was compared with a chisquare test. The same test was not performed in 2011 due to limited captures in all orchards.

2.4. Injury Assessments. In 2010, fruit were evaluated weekly from 30 July to harvest, relative to each cultivar, for the presence of stink bug damage in apples and peaches. One hundred apples and one hundred peaches were picked from both the exterior and interior at each commercial orchard. The exterior was limited to the three outermost rows of each plot and was bordered by a wooded/wild habitat; while interior fruit were selected from the middle third of each plot. The surface of each fruit was visually examined and the side of the fruit appearing to have the greatest number of injury sites was sectioned to the core. The total number of injured fruit and independent injury sites on one side of the fruit, indicated by the presence of subsurface corking
(Figures 2 and 3(b)), was recorded. In 2011, fruit evaluations were conducted weekly from 18 May to harvest of each cultivar using a similar protocol to that established in 2010 . Evaluations were conducted prior to 18 May as on-tree visual samples of the surface of both 100 apples and peaches, but proved too unreliable to accurately assess the level of injury and so all subsequent evaluations involved removal of fruit from the tree. Samples prior to 18 May will not be reported in this paper. Thereafter, 200 peaches and 100 apples were destructively sampled weekly from the exterior of each plot. The peach evaluation was the same as that in 2010. This level of recording persisted until 13 July, where the protocol returned to that of 2010. Due to variation in expression of injury in apple relative to fruit maturity, the entire surface of each apple was evaluated for the presence of a feeding hole or dimple until apple injury was expressed as a depression or discolored depression [25]. At this time, fruit were sectioned to the core, and the total number of injured fruit, based on the presence of corking in the flesh (Figure 3), was recorded. In 2011, only the exterior of each apple and peach plot was sampled until $5 \%$ of fruit contained at least one subsurface corky spot. Once an interior sample was triggered, only 100 fruit of each species were sampled. Thus, from August on, fruit were evaluated for the presence of corking in the flesh and the number of individual corking spots. Percent corking injury and number of injury sites per injured fruit on the exterior and interior of plots were compared using a Student's $t$-test and percentages were arcsin-square root transformed as needed.

\section{Results}

\subsection{Aggregate Insecticide Metric}

3.1.1. Apple. At all four commercial orchards, growers increased the number of brown marmorated stink bug-targeted insecticide applications and decreased the time between 

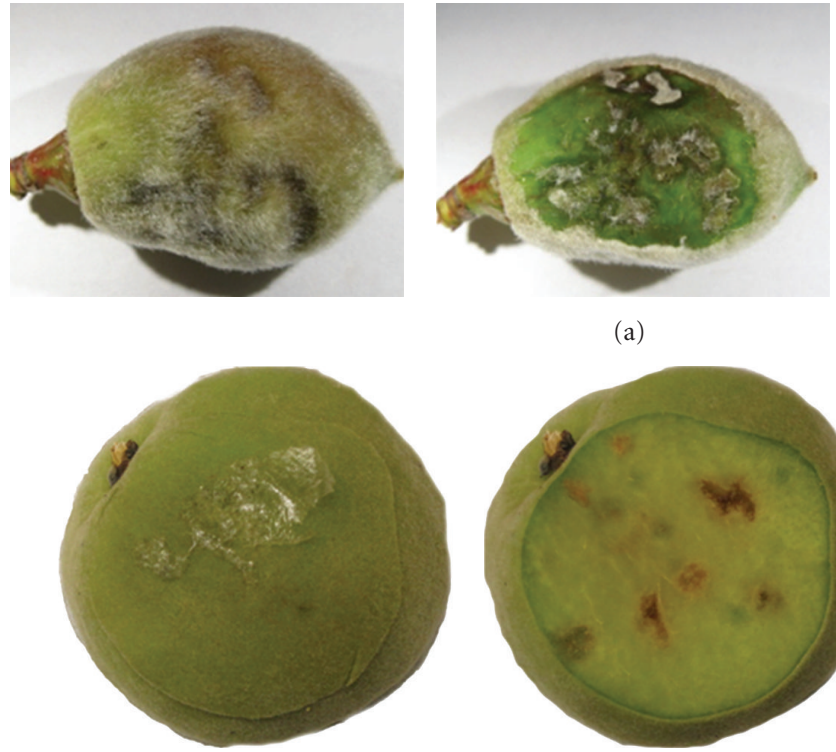

(a)
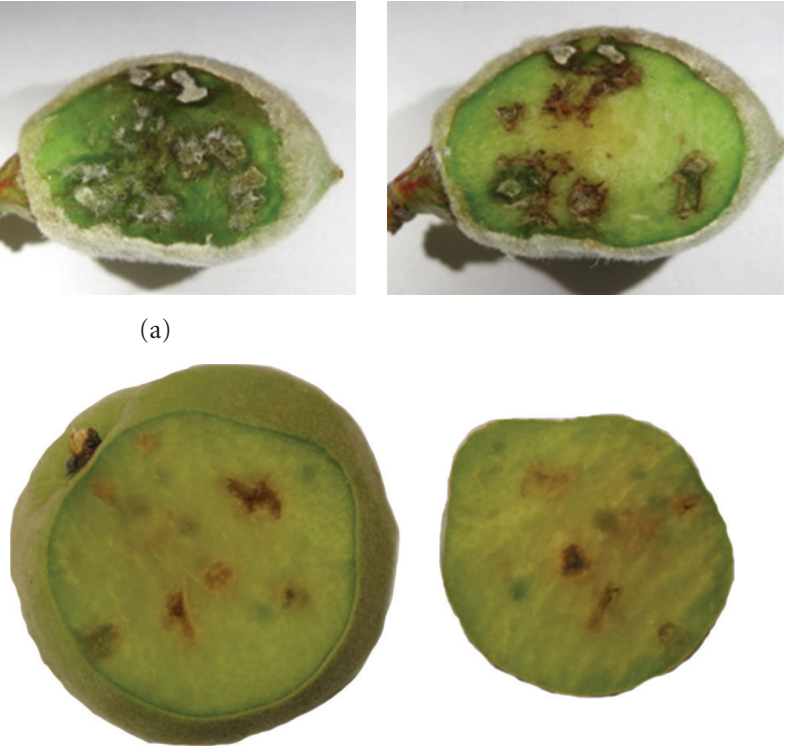

(b)

Figure 2: (a) Photos of subsurface corking injury to a $15 \mathrm{~mm}$ "Loring" peach in the early season and to (b) a $40 \mathrm{~mm}$ "Red Haven" peach 3 weeks prior to harvest.

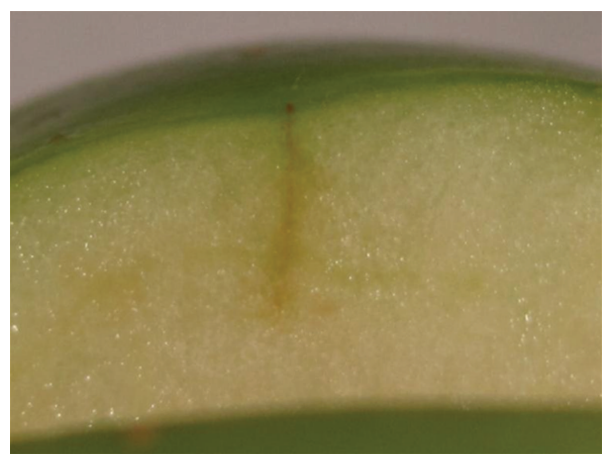

(a)

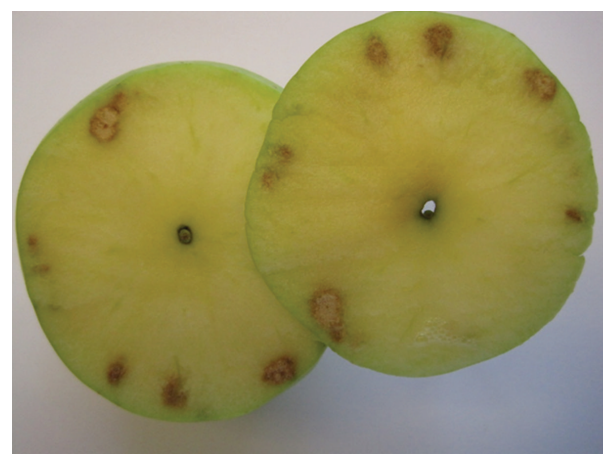

(b)

Figure 3: (a) Photo of subsurface feeding sheath that is the result of feeding in the early season on "Golden Delicious" apple and of (b) subsurface corking injury on "Turley Winesap" which is the result of feeding taking place later in the season (from $\sim 6-8$ weeks after petal fall until harvest).

consecutive applications from 2010 to $2011(t=5.67$; $\mathrm{df}=118 ; P<0.0001)$. The total AIM score increased numerically from 2010 to 2011, but there was no statistical difference in the mean AIM score $(t=1.078$; $\mathrm{df}=150 ; P=$ 0.2827) (Table 1).

3.1.2. Peach. At all four commercial orchards, growers increased the number of brown marmorated stink bug-targeted insecticide applications and decreased the time between consecutive applications $(t=3.45 ; \mathrm{df}=86 ; P=0.0009)$. The mean AIM score increased significantly $(t=2.486$; $\mathrm{df}=109$; $P=0.0144)$ and total AIM score also increased from 2010 to 2011 (Table 2).

\subsection{Sampling/Monitoring}

3.2.1. Apple. Orchard A yielded a total of 12 brown marmorated stink bugs in limb jarring, 21 in sweep net, and 77 in visual samples season-long. At orchard C, 9 brown marmorated stink bugs were collected in limb jarring samples, 14 from sweep nets, and 49 in visual observations season long (Figure 4(a)).

3.2.2. Peach. At orchard A, a total of 3 brown marmorated stink bugs were recovered from limb jarring samples, 4 from visual observations and 0 from sweep net ground samples season-long. No brown marmorated stink bugs were 


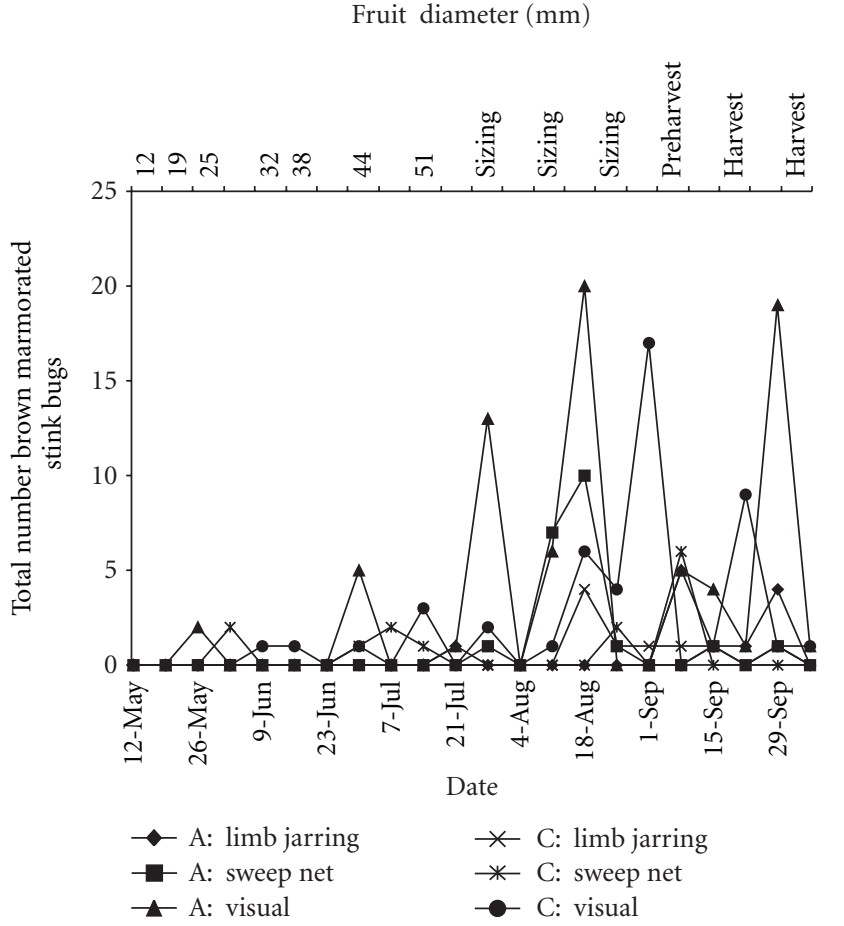

(a)
Fruit diameter $(\mathrm{mm})$

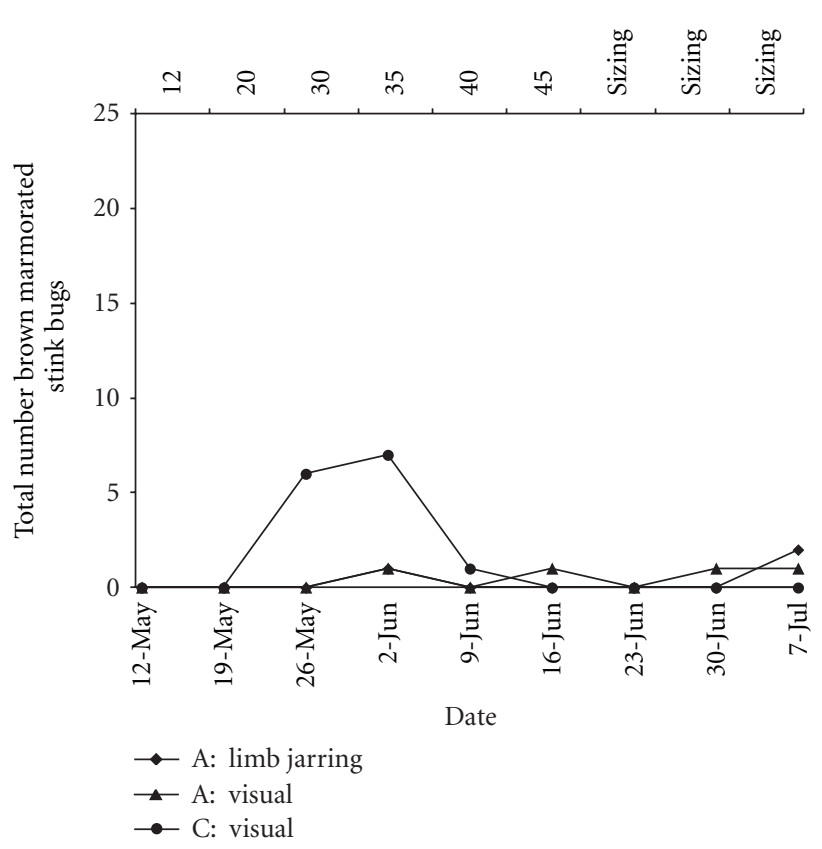

(b)

FIgURE 4: (a) Total number of brown marmorated stink bug eggs, nymphs, and adults recovered from limb jarring, sweep net, and visual samples in apple trees and (b) the total number recovered from limb jarring and visual samples in peach trees at orchard A and C in 2011.

TABLE 1: Total number of targeted brown marmorated stink bug insecticide applications, mean interval (d) \pm SEM between insecticide applications, and mean A.I.M. score \pm SEM and total A.I.M. score in apple plots from 2010 to 2011 at four commercial orchards.

\begin{tabular}{lccccccrr}
\hline Orchard & \multicolumn{2}{c}{$\begin{array}{c}\text { Number of targeted } \\
\text { insecticide applications }\end{array}$} & \multicolumn{2}{c}{$\begin{array}{c}\text { Mean insecticide } \\
\text { interval } \pm \text { SEM }\end{array}$} & \multicolumn{3}{c}{ A.I.M. score } \\
Mean \pm SEM* & 2010 & 2011 & 2010 & 2011 \\
\hline A & 2010 & 2011 & 20 & $10.6 \pm 1.9$ & $7.2 \pm 0.4$ & $0.06 \pm 0.02$ & $0.19 \pm 0.02$ & 0.89 \\
B & 3 & 7 & $22.2 \pm 5.7$ & $18.8 \pm 2.5$ & $0.40 \pm 0.10$ & $0.46 \pm 0.10$ & 3.63 & 5.47 \\
C & 5 & 12 & $18.5 \pm 1.3$ & $11.4 \pm 1.4$ & $0.18 \pm 0.05$ & $0.29 \pm 0.06$ & 1.78 & 5.31 \\
D & 4 & 42 & $10.6 \pm 1.0$ & $4.1 \pm 0.3$ & $0.21 \pm 0.05$ & $0.18 \pm 0.02$ & 3.28 & 8.16 \\
\hline All Orchards & 7 & 81 & $14.0 \pm 1.3 \mathrm{a}$ & $7.1 \pm 0.6 \mathrm{~b}$ & $0.20 \pm 0.03 \mathrm{a}$ & $0.24 \pm 0.02 \mathrm{a}$ & 9.58 & 24.2 \\
\hline
\end{tabular}

* Means for all orchards combined, compared between years within a paired column, followed by a different letter are significantly different $(P<0.05)$.

collected in sweep net or limb jarring samples at orchard $\mathrm{C}$ and a total of 14 brown marmorated stink bugs were observed in visual samples between 25 May and 7 June with no other bugs documented for the remainder of the season (Figure 4(b)).

3.3. Trapping. In all four commercial apple plots sampled from August to November in 2010 and 2011, the number of adults $(t=3.81 ; \mathrm{df}=60.776 ; P=0.0003)$ and nymphs $(t=$ 2.49 ; $\mathrm{df}=59.108 ; P=0.0155)$ captured was significantly lower in 2011 (Figure 5(a)). On 8 September 2010, there was a significant shift in the ratio of adults:nymphs captured in traps at all orchards $\left(\chi^{2}=1762.3737 ; \mathrm{df}=1 ; P<0.0001\right)$. Prior to that date, significantly fewer adults were captured than nymphs at Orchard A $\left(\chi^{2}=21586.7131 ; \mathrm{df}=1\right.$;
$P<0.0001), \mathrm{C}\left(\chi^{2}=3410.2565 ; \mathrm{df}=1 ; P<0.0001\right)$, and $\mathrm{D}\left(\chi^{2}=78.5714 ; \mathrm{df}=1 ; P<0.0001\right)$; however there was no difference between adult and nymph captures at orchard $\mathrm{B}\left(\chi^{2}=1.5077 ; \mathrm{df}=1 ; P=0.2195\right)$. During the entire 2011 growing season, very few adults or nymphs were captured in traps deployed in apple and peach blocks; however, those that were captured were primarily recovered after July (Figure 5). In fact, $72 \%$ of all adult captures were recovered from traps on 29 September 2011.

\subsection{Injury Assessments}

3.4.1. Apple: 2010. In 2010, significantly more apples were injured on the plot exterior than in the interior at orchards A $(t=2.18 ; \mathrm{df}=18.836 ; P=0.0421), \mathrm{B}(t=4.48 ; \mathrm{df}=15.964$; 


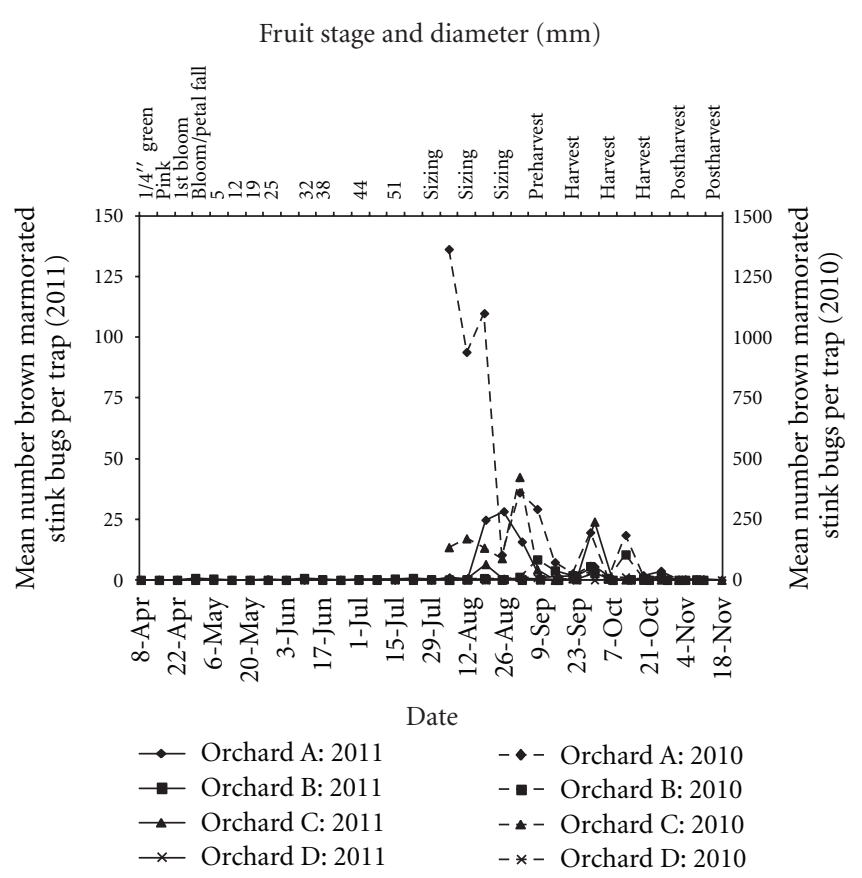

(a)
Fruit stage and diameter $(\mathrm{mm})$

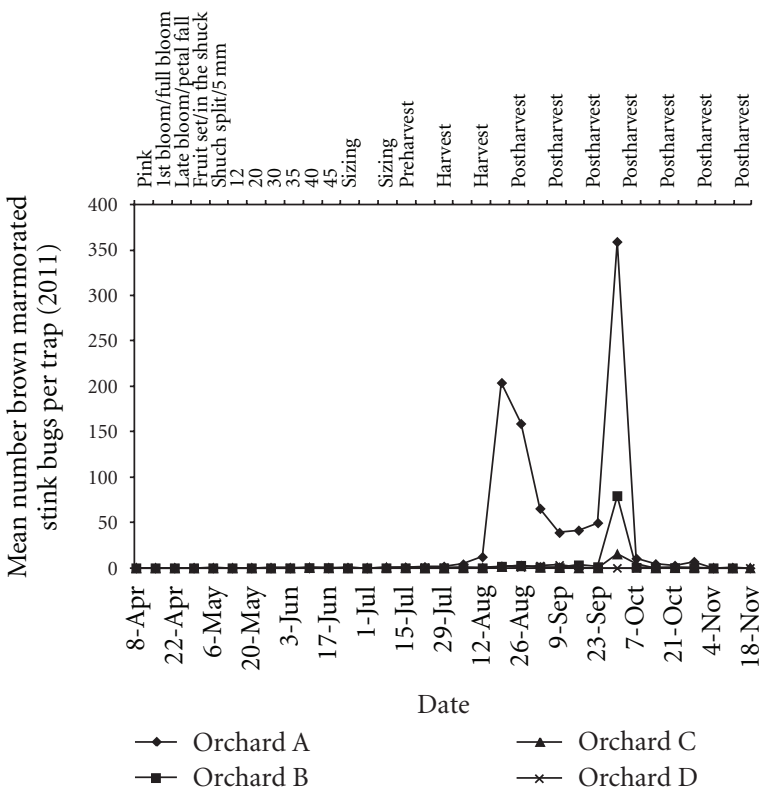

(b)

FIGURE 5: Mean number of brown marmrorated stink bug adults and nymphs captured per trap at orchards A-D in (a) apple in 2010 and 2011 and (b) peach plots in 2011.

TABLE 2: Total number of targeted brown marmorated stink bug insecticide applications, mean interval (d) \pm SEM between insecticide applications, and mean A.I.M. score \pm SEM and total A.I.M. score in peach plots from 2010 to 2011 at four commercial orchards.

\begin{tabular}{lcccccccc}
\hline Orchard & \multicolumn{2}{c}{$\begin{array}{c}\text { Number of targeted } \\
\text { insecticide applications }\end{array}$} & \multicolumn{2}{c}{ Mean interval insecticide } & \multicolumn{3}{c}{ A.I.M. score } \\
interval + SEM $^{*}$ & \multicolumn{2}{c}{ Mean \pm SEM } & \multicolumn{2}{c}{ Total } \\
& 2010 & 2011 & 2010 & 2011 & 2010 & 2011 & 2010 & 2011 \\
\hline $\mathrm{A}$ & 4 & 16 & $8.5 \pm 1.0$ & $6.7 \pm 0.3$ & $0.14 \pm 0.03$ & $0.30 \pm 0.03$ & 1.67 \\
$\mathrm{~B}$ & 6 & 8 & $16.0 \pm 1.9$ & $15.7 \pm 1.4$ & $0.16 \pm 0.03$ & $0.25 \pm 0.04$ & 2.13 & 2.72 \\
$\mathrm{C}$ & 4 & 9 & $17.0 \pm 3.2$ & $14.1 \pm 1.2$ & $0.24 \pm 0.06$ & $0.30 \pm 0.02$ & 2.12 & 3.26 \\
$\mathrm{D}$ & 6 & 22 & $12.0 \pm 2.6$ & $4.5 \pm 0.9$ & $0.23 \pm 0.05$ & $0.18 \pm 0.02$ & 2.73 & 4.38 \\
\hline All Orchards & 20 & 55 & $12.8 \pm 1.2 \mathrm{a}$ & $8.1 \pm 0.8 \mathrm{~b}$ & $0.18 \pm 0.02 \mathrm{a}$ & $0.25 \pm 0.01 \mathrm{~b}$ & 8.65 & 16.09 \\
\hline
\end{tabular}

*Means for all orchards combined, compared between years within a paired column, followed by a different letter are significantly different $(P<0.05)$.

$P=0.0004)$, and $\mathrm{C}(t=2.64 ; \mathrm{df}=9.4638 ; P=0.0258) ;$ however, there was no statistical difference at orchard $\mathrm{D}(t=$ $0.87 ; \mathrm{df}=14.901 ; P=0.4007)$ (Figure 6(a)). No differences in the number of injury sites were observed between apples on the exterior or interior of plots for any orchard (A: $t=$ $1.20 ; \mathrm{df}=19.761 ; P=0.2452, \mathrm{~B}: t=1.02 ; \mathrm{df}=15.96 ; P=$ $0.3211, \mathrm{C}: t=1.38 ; \mathrm{df}=11.963 ; P=0.1923, \mathrm{D}: t=-0.22$; $\mathrm{df}=14.474 ; P=.8273)($ Figure $6(\mathrm{~b}))$.

3.4.2. Peach: 2010 . Fruit sampling in peach started relatively close to harvest in 2010, so few samples were available for comparison and thus only data summaries were performed. The percent injury and number of injury sites recorded at harvest did not vary greatly from injury recorded at the first sample. Orchard A and B had more injured fruit on the exterior; however the reverse was true at orchard D. There was no interior peach sample at orchard $\mathrm{C}$ due to the size and layout of the plot. At the three orchards that had both exterior and interior peach samples, the number of injury sites per injured fruit was higher on the exterior of the plots (Figures 7(a) and 7(b)).

3.4.3. Apple: 2011. In 2011, significantly more apples were injured on the plot exterior than in the interior at orchard A $(t=2.89 ; \mathrm{df}=10.473 ; P=0.0153), \mathrm{C}(t=6.43 ; \mathrm{df}=24 ; P<$ $0.0001)$, and $\mathrm{D}(t=2.61 ; \mathrm{df}=18.507 ; P=0.0174)$; however, there was no statistical difference at orchard $\mathrm{B}(t=1.75 ; \mathrm{df}=$ 6.8897; $P=0.1235)$ (Figure 8(a)). Only orchard C $(t=2.53$; $\mathrm{df}=21.895 ; P=0.0189)$ had significantly more injury sites per injured apple on the plot exterior than on the interior (Figure 8(b)). 

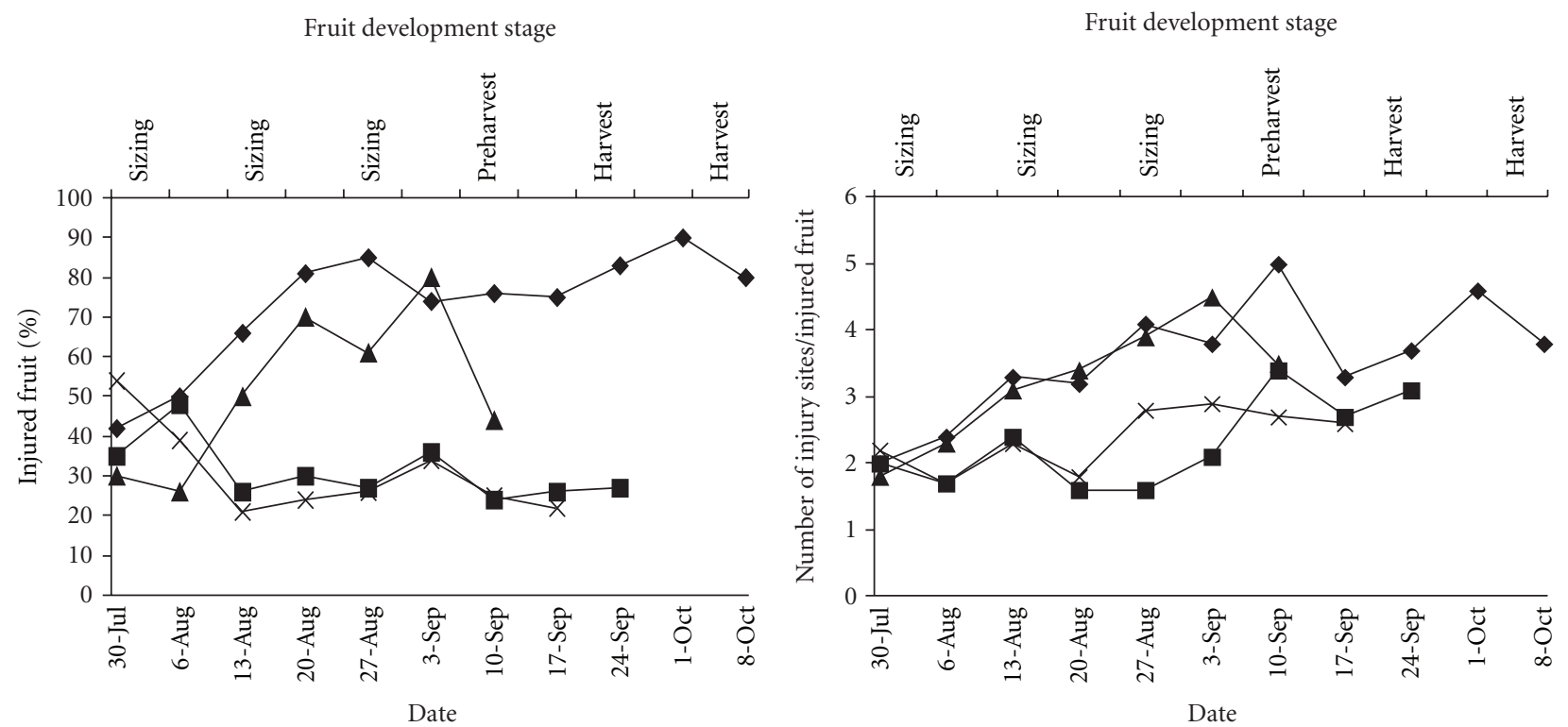

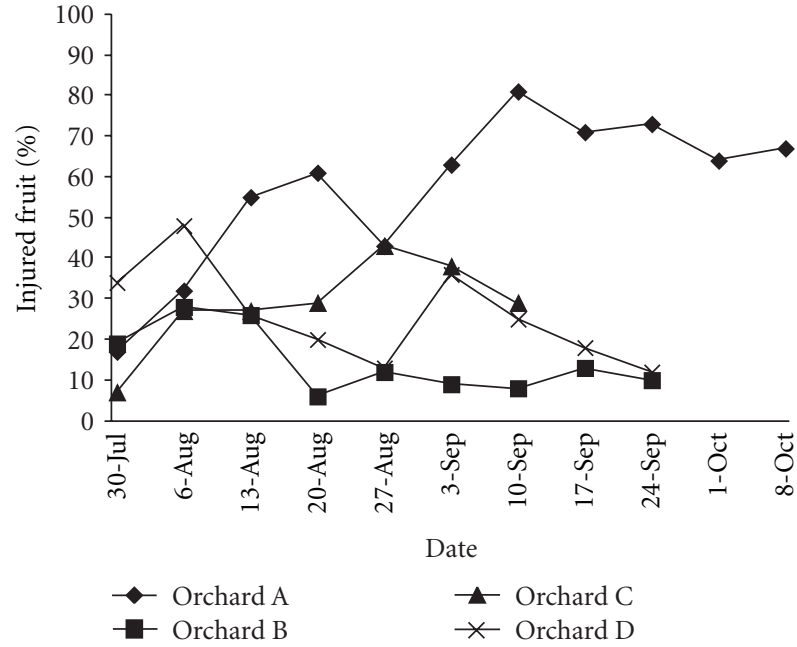

(a)

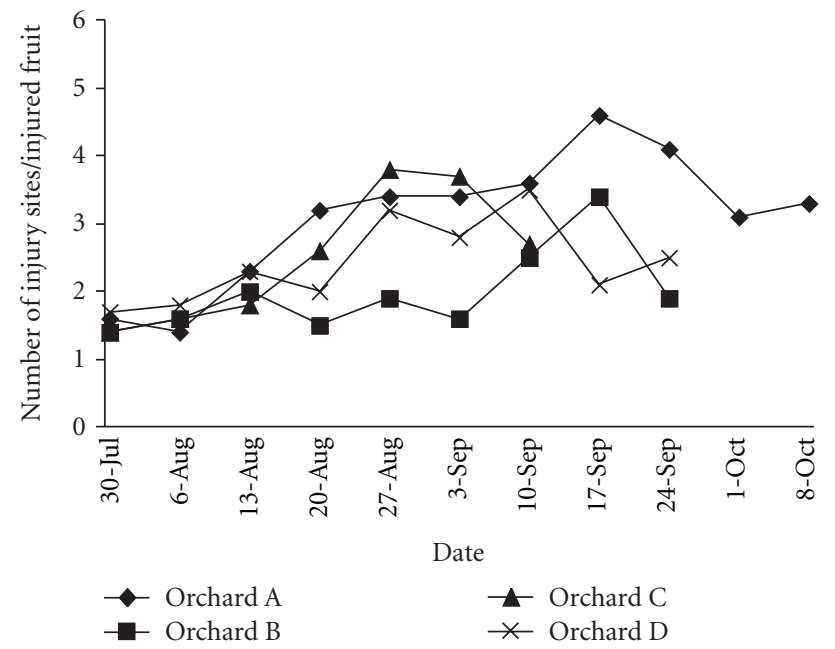

(b)

Figure 6: (a) Percent injured apples in 2010 at orchards A-D from the plot exterior (top) and interior (bottom) and (b) the number of injury sites per injured fruit in 2010 at orchards A-D in the plot exterior (top) and interior (bottom).

3.4.4. Peach: 2011. In the peach plots, orchard $\mathrm{B}(t=2.13$; $\mathrm{df}=17 ; P=0.0477)$ and $\mathrm{D}(t=3.34 ; \mathrm{df}=17.451 ; P=$ 0.0038 ) had significantly more injured fruit on the exterior than in the interior, whereas there was no difference at orchard A $(t=-0.50 ; \mathrm{df}=16.598 ; P=0.6230)$ or $\mathrm{C}(t=$ $-0.46 ; \mathrm{df}=13.548 ; P=0.6548)$ (Figure $9(\mathrm{a})$ ). Only orchard $\mathrm{B}(t=4.14 ; \mathrm{df}=4 ; P=0.0143)$ had significantly more injury sites per injured peach on the exterior of the plot than the interior; there was no difference at the other orchards (Figure 9).

3.4.5. Apple: 2010 versus 2011. Finally, significantly more apples were injured from 30 July through harvest in total in 2010 than 2011 at each orchard (A: $t=13.25$; $\mathrm{df}=40$; $P<0.0001, \mathrm{~B}: t=5.03$; df $=33 ; P<0.0001, \mathrm{C}: t=5.32$; $\mathrm{df}=38 ; P<0.0001, \mathrm{D}: t=5.69 ; \mathrm{df}=40 ; P<0.0001)$.
Likewise, the total number of injury sites per injured fruit was significantly greater in 2010 than 2011 at orchard A $(t=6.51 ; \mathrm{df}=34.78 ; P<0.0001), \mathrm{C}(t=2.45 ; \mathrm{df}=25.765$; $P=0.0212)$, and $\mathrm{D}(t=4.83 ; \mathrm{df}=32.231 ; P<0.0001)$, but not at orchard B $(t=1.74 ; \mathrm{df}=26.376 ; P=0.0940)$.

3.4.6. Peach: 2010 versus 2011. No statistical comparisons were performed due to minimal peach samples collected in orchards in 2010. However, injury was generally higher in both exterior and interior samples in 2010 compared with 2011 at harvest.

\section{Discussion}

Brown marmorated stink bug has been documented as utilizing apple as a host in Japan [26] and the United States 

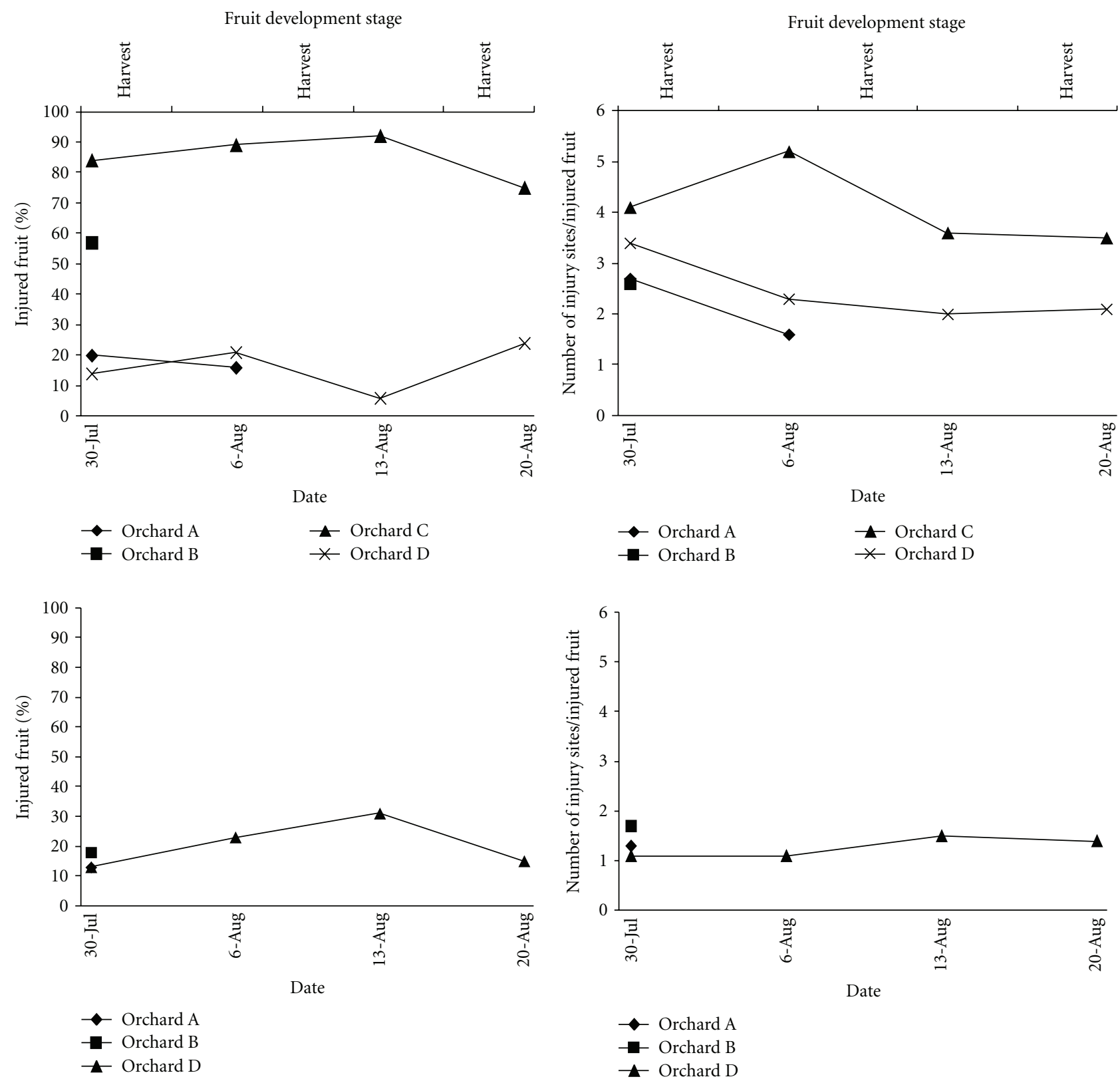

(a)

(b)

Figure 7: (a) Percent injured peaches in 2010 at orchards A-D from the plot exterior (top) and interior (bottom) and (b) the number of injury sites per injured fruit in 2010 at orchards A-D in the plot exterior (top) and interior (bottom).

[6]. Nielsen and Hamilton [7] found that based on a caging study, injury was significantly greater during the late-season compared with petal fall or mid-season. In our studies, we found that natural populations of brown marmorated stink bug in commercial apple blocks will feed on fruit throughout the season, but like native stink bug species [25], feeding injury that occurs in the early season results in a small feeding puncture in the fruit skin and nominal injury to the flesh, while injury inflicted 6-8 weeks after petal fall until harvest results in indented depressions on the surface of the fruit with corky flesh beneath $[25,27]$. However, like native stink bugs $[25,27]$ injury symptoms may take several weeks to manifest completely (S. Joseph, personal communication). Native stink bugs found in mid-Atlantic tree fruit orchards in the United States include Euschistus servus, E. tristigmus, and $C$. hilaris predominantly [11]. These species will feed on many cultivars of apples, though higher injury rates have been recorded, in one study, on "Braeburn," "Jonica," "Jonagold," "Starkspur Dixiered," "Granny Smith" and "Stayman" [28]. However in our study, no direct comparisons of cultivar susceptibility were conducted. Injury patterns within apple blocks indicate the brown marmorated stink bug is a perimeter-driven threat. Indeed in 2010 and 2011, injury was usually significantly greater at the exterior of orchard blocks 

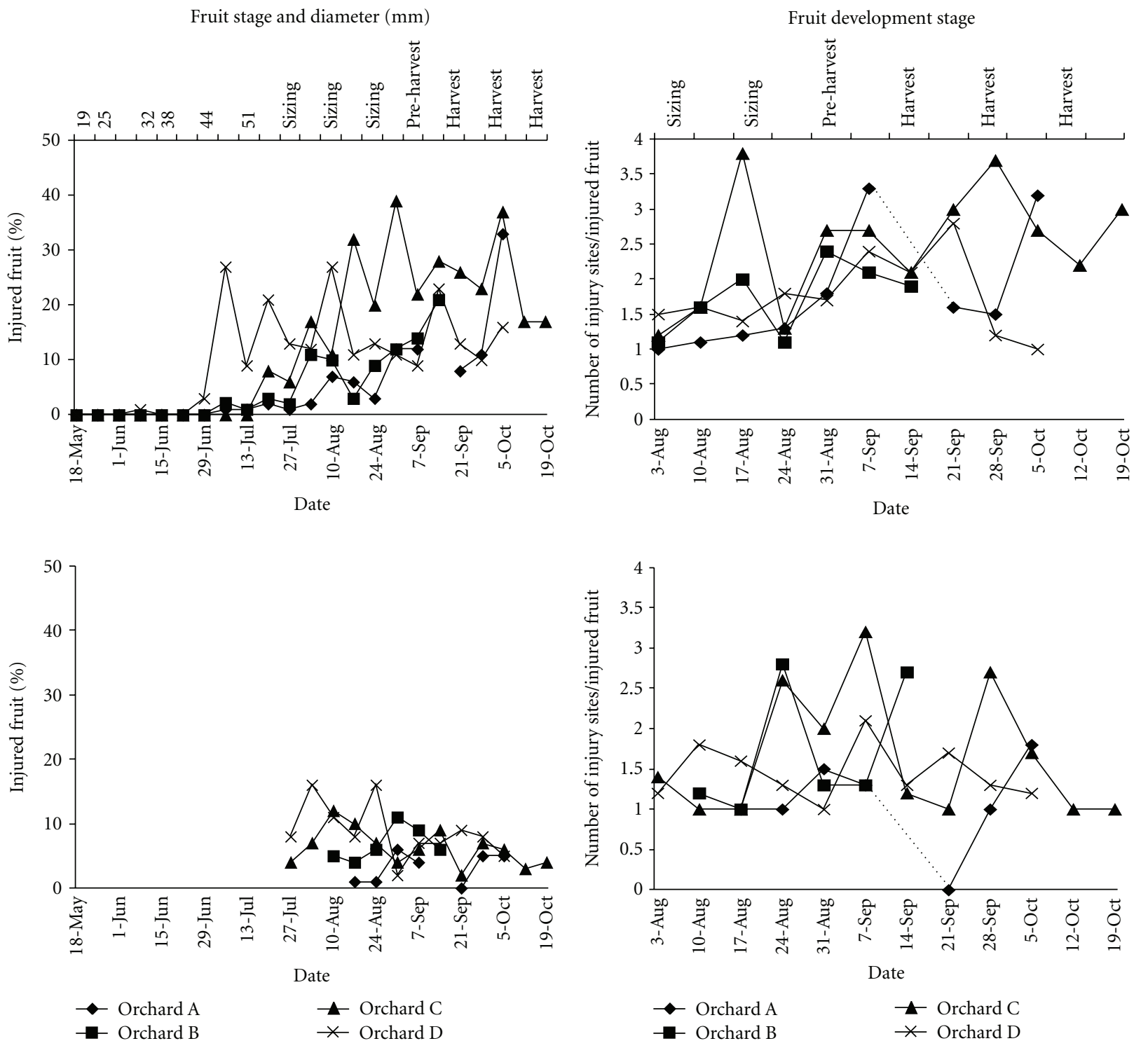

(a)

(b)

Figure 8: (a) Percent injured apples in 2011 at orchards A-D from the plot exterior (top) and interior (bottom) and (b) the number of injury sites per injured fruit in 2011 at orchards A-D in the plot exterior (top) and interior (bottom). Note: the dotted lines in $8 \mathrm{~B}$ represent missing data on 14 September.

relative to the interior suggesting that adults, emigrating from overwintering sites in the early season and from wood lots or cultivated hosts such as corn and soybean later in the season, constantly invade orchards. Similar patterns of movement have been observed for native stink bug species in other cropping systems $[29,30]$.

Peach is also an excellent host for brown marmorated stink bug. In cage studies, brown marmorated stink bug caused the greatest injury during the late season [7]. In our studies, natural populations of adults have proven to be extremely damaging in commercial peach orchards in the early season soon after fruit set. In 2011, large numbers of adults moving from overwintering sites began to target the developing peach fruit by 1 June $(\sim 30 \mathrm{~mm}$ diameter fruit); two orchards had already recorded over $20 \%$ damage. In 2010, early-season feeding by adults led to devastating injury to peach growers in many mid-Atlantic states [8]. Unlike apple injury, peach symptoms appeared to manifest very quickly after feeding, within several days. Typically injury inflicted by native stink bugs results in cat-facing and gummosis [31], while early season brown marmorated stink bug injury, though resulting in gummosis, often results in dead pockets of tissue deep in the flesh of the fruit that are not obvious on the surface as the fruit matures. While native stink bugs are capable of inflicting this type of injury as well, it has proven far more prevalent from brown marmorated stink bug. Damage in commercial peach blocks was significantly greater in the exterior compared with the 

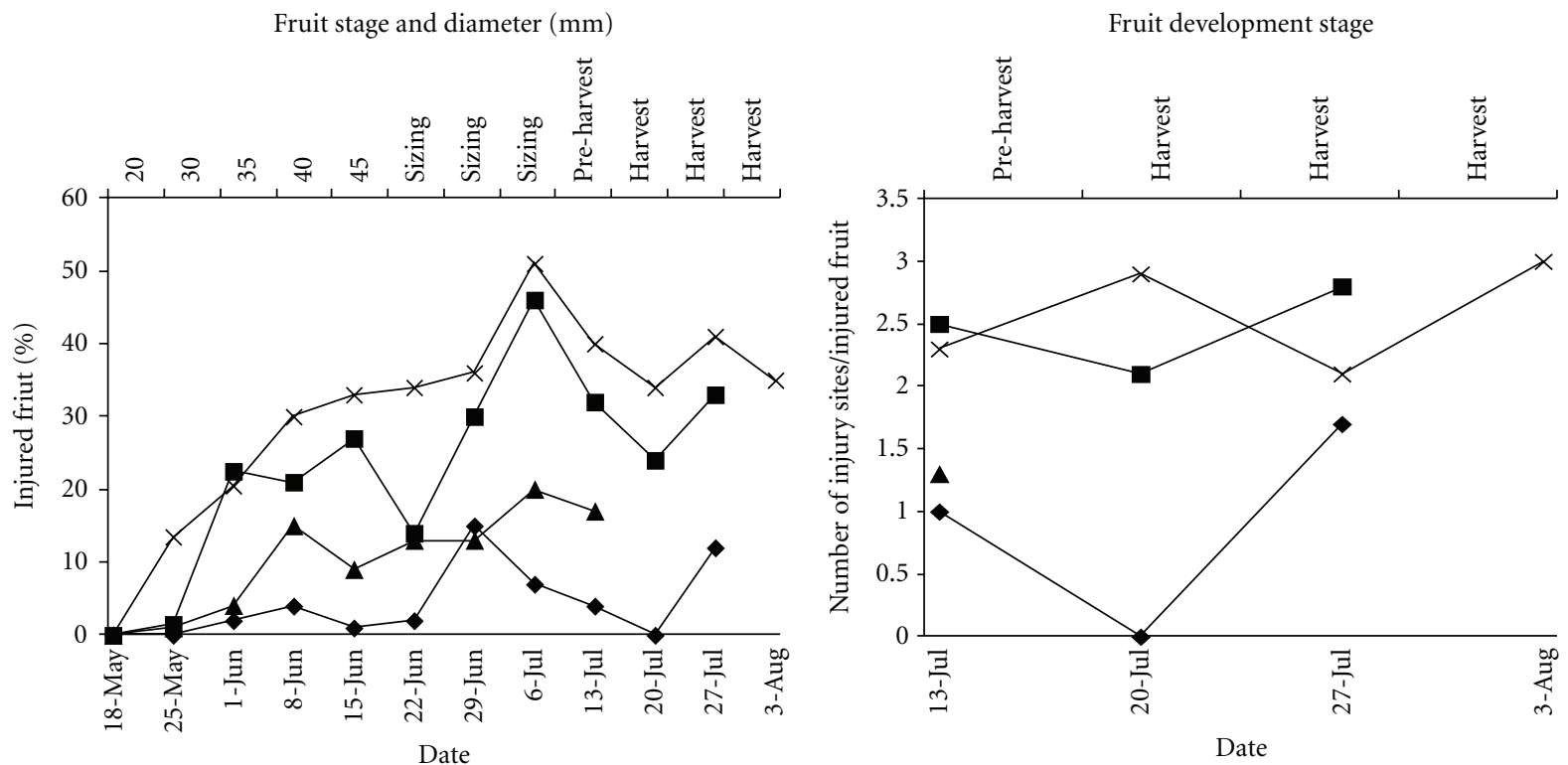

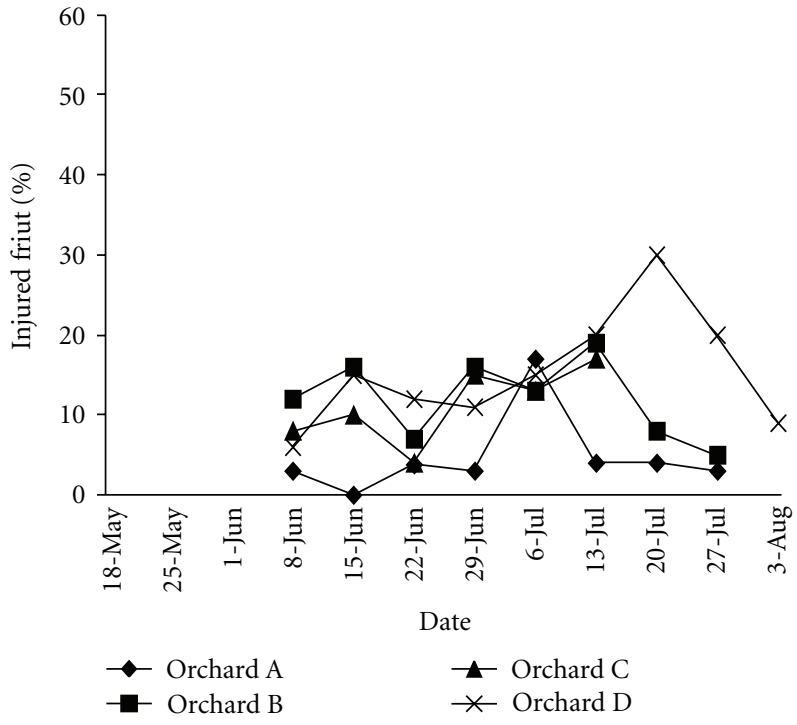

(a)

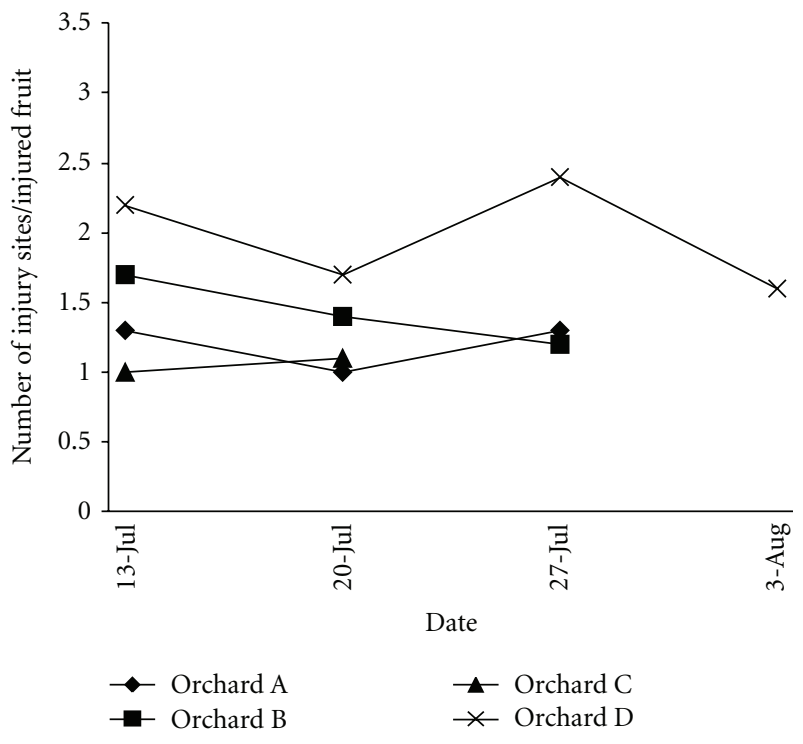

(b)

Figure 9: (a) Percent injured peaches in 2011 at orchards A-D from the plot exterior (top) and interior (bottom) and (b) the number of injury sites per injured fruit in 2011 at orchards A-D in the plot exterior (top) and interior (bottom).

interior, indicating adults were immigrating into blocks from the outside as was found for apple.

Based on the presence of economic injury, peach fruit is vulnerable soon after fruit set and this vulnerability continues to harvest. By contrast, economic injury to apple generally begins $6-8$ weeks after petal fall and can continue until harvest (Figure 8). However, because reproduction can occur in commercial orchards, mitigating treatments must be undertaken early to prevent the threat of nymphal populations contributing to overall injury.

In apple and peach orchard blocks, growers changed their management programs tremendously from 2010 to 2011. In 2010, growers either did not target brown marmorated stink bug specifically or used materials recommended for native stink bugs, particularly pyrethroids. In peach orchards in the southeastern United States, where cat-facing bugs including native stink bugs and tarnished plant bug, Lygus lineolaris Palisot de Beauvois, are considered key pests, control is typically achieved using pyrethroids [32]. Unfortunately, many of these same materials did not provide adequate control of brown marmorated stink bug in 2010, as documented in a field trial in which over $25 \%$ of moribund bugs exposed to cyfluthrin in treated apple canopies recovered to an actively foraging state [16]. Furthermore, in laboratory trials, treatments of beta-cyfluthrin, lambda-cyhalothrin, zeta-cypermethrin, cyfluthrin, and esfenvalerate resulted in high initial knockdown of adults, but also high levels of recovery [15]. 
Thus, in 2011, growers relied on materials such as endosulfan, methomyl, permethrin, fenpropathrin, dinotefuran, clothianidin, and thiamethoxam. All of these materials not only demonstrated high levels of immediate knockdown, but also very little recovery [15]. In general, the mean AIM score showed that a more intense insecticide program was implemented in 2011 in response to the threat posed by brown marmorated stink bug. Likewise, the total AIM score illustrates that growers used more of these targeted spray applications in 2011 than in 2010. In addition, growers shortened the intervals between insecticide applications from 2010 to 2011. For apple plots in 2010, growers sprayed at approximately 2-wk intervals but cut that to a 1-wk interval in 2011. Similarly in peach plots in 2010 growers, treated at approximately 13 -d intervals but shortened that to 8 -d intervals in 2011. These factors likely contributed to both the decrease in overall percent injury and lower trap captures. However, the sustainability of this type of program financially and ecologically is not feasible and growers will certainly need to implement a sensitive and reliable monitoring program for future seasons.

Monitoring tools can be used to effectively assess presence, abundance, and seasonal activity of a pest species, allowing growers to make informed management decisions. In 2010 and 2011, we evaluated the use of black pyramid traps baited with methyl-(2E,4E,6Z)-decatrienoate as a monitoring tool for brown marmorated stink bug populations. This trap and lure combination had been previously shown effective at capturing large numbers of adults and nymphs of brown marmorated stink bug [21]. Significantly more adults were captured in traps in 2010 compared with 2011. This pattern likely reflects four key considerations. First, in 2010, as stated above, growers were not specifically targeting brown marmorated stink bug with insecticide applications, allowing adults to reproduce and populations to build within the orchards. Second, weather patterns were quite different between years. In 2010, a second generation of adults had completed development by 13 September [21], whereas in 2011, development was not complete until 11 October (Leskey, unpublished data). Based on developmental rates developed by Nielsen et al. [33], degree day accumulations required for completion of the second generation were much slower in 2011, possibly leading to much smaller populations observed and subsequently trapped. Third, a different trap top was used in 2011 than in 2010. This trap top has subsequently been reported to be less effective in capturing and/or retaining brown marmorated stink bugs. Finally, differences in overall lure effectiveness may exist between 2010 and 2011 based on overall trap captures and release rates [34] contributing to lower captures in 2011.

However, more problematic is the fact that very few adults were captured in traps throughout the growing season in 2011. It is true that growers instituted season-long management programs in 2011 against brown marmorated stink bug; however, injury rates early in the season indicate that adults were surely present. Funayama [35] captured brown marmorated stink bug adults using traps baited with methyl-(2E,4E,6Z)-decatrieonate early in the season during outbreak years. However, our traps did not recover adults, even remotely reflective of observed populations, until mid-August in apple. Indeed, greatest trap captures actually occurred in peach orchards after the fruit was harvested. Thus, other monitoring techniques were evaluated. As evaluated for native stink bugs in the mid-Atlantic [11], we tested the use of sweep nets and limb jarring samples in commercial orchards season-long in 2011. Almost no bugs were recovered from these sampling techniques indicating that they did not adequately reflect the presence, size, or activity of populations. Timed visual counts also were conducted and did result in greater numbers of bugs being observed, but again the numbers were too low to adequately reflect population density or activity. It is likely that observed behavioral attributes of brown marmorated stink bug are not compatible with these sampling techniques. For example, brown marmorated stink bug has a tendency to be found high in the tree (Short, personal observation) lending to difficulty in obtaining individuals from limb jarring samples taken at head-height or below. Adults have not been observed feeding on many broad-leaf weeds based on host surveys conducted to date [5], which could lead to fewer captures in sweep nets. Likewise, diurnal patterns are not well understood. Certainly, adults and nymphs have been observed actively feeding and mating at night by numerous researchers.

Although cross attraction to methyl-(2E,4E,6Z)-decatrieonate has been observed for brown marmorated stink bug [21] as well as other species including C. hilaris [36], it is not attractive to brown marmorated stink bug adults seasonlong. Thus, identification of the aggregation pheromone of this species could provide a better tool to use with baited traps. Additionally, brown marmorated stink bug adults do respond to visible light (Leskey, unpublished data) and to ultraviolet light as they have been captured in black light traps [6]. Perhaps, creating a trap with optimized olfactory and visual stimuli including the true aggregation pheromone and specific wavelengths of light could provide a much more sensitive monitoring tool that is attractive season-long and can be used to develop treatment thresholds for this invasive species. In the interim, however, it is likely that growers still will need to continue with aggressive management programs aimed at this invasive species in order to mitigate economic injury and successfully grow tree fruit in regions where it is well established.

\section{Acknowledgments}

The authors thank J. Cullum, T. Hancock, R. Posa, C. Scorza, and S. Wiles for excellent technical support and the commercial growers in West Virginia and Maryland who cooperated with the studies. This paper was supported by a specific cooperative agreement with USDA-APHIS and by USDA-NIFA SCRI no. 2011-51181-30937.

\section{References}

[1] E. R. Hoebeke and M. E. Carter, "Halyomorpha halys (Stål) (Heteroptera: Pentatomidae): a polyphagous plant pest from Asia newly detected in North America," Proceedings of the 
Entomological Society of Washington, vol. 105, no. 1, pp. 225237, 2003.

[2] B. Wermelinger, D. Wyniger, and B. Forster, "First records of an invasive bug in Europe: Halyomorpha halys Stål (Heteroptera: Pentatomidae), a new pest on woody ornamentals and fruit trees?" Mitteilungen der Schweizerischen Entomologischen Gesellschaft, vol. 81, pp. 1-8, 2008.

[3] R. Fogain and S. Graff, "First records of the invasive pest, Halyomorpha halys(Hemiptera: Pentatomidae) in Ontario and Quebec," Journal of the Entomological Society of Ontario, vol. 142, pp. 45-48, 2011.

[4] A. R. Panizzi, J. E. McPherson, D. G. James, M. Javahery, and B. A. McPherson, "Stink bugs (Pentatomidae)," in Heteroptera of Economic Importance, C. W. Schaefer and A. R. Panizzi, Eds., p. 828, CRC, New York, NY, USA, 2000.

[5] G. Bernon, "Biology of Halyomorpha halys. The brown marmorated stink bug," Tech. Rep., United States Department of Agriculture, Animal and Plant Health Inspection Service, Center for Plant Health Science Technology, 2004.

[6] A. L. Nielsen and G. C. Hamilton, "Life history of the invasive species Halyomorpha halys (Hemiptera: Pentatomidae) in northeastern United States," Annals of the Entomological Society of America, vol. 102, no. 4, pp. 608-616, 2009.

[7] A. L. Nielsen and G. C. Hamilton, "Seasonal occurrence and impact of Halyomorpha halys (Hemiptera: Pentatomidae) in tree fruit," Journal of Economic Entomology, vol. 102, no. 3, pp. 1133-1140, 2009.

[8] T. C. Leskey and G. C. Hamilton, Brown marmorated stink bug working group meeting, June 2011 report, http://projects .ipmcenters.org/Northeastern/FundedProjects/ReportFiles/ Pship2010/Pship2010-Leskey-FinalReport-Meeting-June2011-237195.pdf.

[9] United States Apple Association, "Asian pest inflicting substantial losses, raising alarm in eastern apple orchards," Apple News, vol. 41, no. 8, p. 488, 2010.

[10] H. W. Hogmire and T. C. Leskey, "An improved trap for monitoring stink bugs (Heteroptera: Pentatomidae) in apple and peach orchards," Journal of Entomological Science, vol. 41, no. 1, pp. 9-21, 2006.

[11] T. C. Leskey and H. W. Hogmire, "Monitoring stink bugs (Hemiptera: Pentatomidae) in mid-Atlantic apple and peach orchards," Journal of Economic Entomology, vol. 98, no. 1, pp. 143-153, 2005.

[12] A. L. Nielsen, P. W. Shearer, and G. C. Hamilton, "Toxicity of insecticides to Halyomorpha halys (Hemiptera: Pentatomidae) using glass-vial bioassays," Journal of Economic Entomology, vol. 101, no. 4, pp. 1439-1442, 2008.

[13] L. A. Hull and V. A. Starner, "Impact of four synthetic pyrethroids on major natural enemies and pests of apple in Pennsylvania," Journal of Economic Entomology, vol. 76, pp. 122$130,1983$.

[14] L. A. Hull, E. H. Beers, and R. L. Meagher, "Impact of selective use of synthetic pyrethroid fenvalerate on apple pests and natural enemies in large-orchard trials," Journal of Economic Entomology, vol. 78, pp. 163-168, 1985.

[15] T. C. Leskey, D-H. Lee, B. D. Short, and S. E. Wright, "Impact of insecticides on the invasive Halyomorpha halys (Stål) (Hemiptera: Pentatomidae): analysis of insecticide lethality," Journal of Economic Entomology. Accepted.

[16] T. C. Leskey, "Brown marmorated stink bug, Halyomorpha halys (Stål), in the East: emergence of an invasive stink bug as a serious threat to agriculture," in Proceedings of the Annual Meeting of the Washington State Horticultural Association, 2011.
[17] C. H. Krupke, J. F. Brunner, M. D. Doerr, and A. D. Kahn, "Field attraction of the stink bug Euschistus conspersus (Hemiptera: Pentatomidae) to synthetic pheromone-baited host plants," Journal of Economic Entomology, vol. 94, no. 6, pp. 1500-1505, 2001.

[18] K. L. Kamminga, D. Herbert, T. P. Kuhar, and C. C. Brewster, "Predicting black light trap catch and flight activity of Acrosternum hilare (Hemiptera: Pentatomidae) adults," Environmental Entomology, vol. 38, no. 6, pp. 1716-1723, 2009.

[19] S. Moriya, M. Shiga, and M. Mabuci, "Analysis of light trap records in four major species of fruit piercing stink bugs with special reference to body size variation in trapped adults of Plautia stali Scott," Bulletin of the Fruit Tree Research Station, vol. 14, pp. 79-84, 1987.

[20] H. Sugie, M. Yoshida, K. Kawasaki et al., "Identification of the aggregation pheromone of the brown-winged green bug, Plautia stali Scott (Heteroptera: Pentatomidae)," Applied Entomology and Zoology, vol. 31, no. 3, pp. 427-431, 1996.

[21] T. C. Leskey, S. E. Wright, B. D. Short, and A. Khrimian, "Development of behaviorally based monitoring tools for the brown marmorated stink bug, Halyomorpha halys (Stål) (Heteroptera: Pentatomidae) in commercial tree fruit orchards," Journal of Entomological Science, vol. 47, pp. 76-85, 2012.

[22] J. R. Aldrich, A. Khrimian, X. Chen, and M. J. Camp, "Semiochemically based monitoring of the invasion of the brown marmorated stink bug and unexpected attraction of the native green stink bug (Heteroptera: Pentatomidae) in Maryland," Florida Entomologist, vol. 92, no. 3, pp. 483-491, 2009.

[23] D. G. Pfeiffer, J. C. Bergh, R. D. Fell et al., 2011 Spray Bulletin for Commercial Tree Fruit Growers: Virginia, West Virginia, and Maryland Cooperative Extension, Virginia Cooperative Extension, Virginia, VA, USA, 2011.

[24] L. A. Hull, K. D. Hickey, and W. W. Kanour, "Pesticide usage patterns and associated pest damage in commercial apple orchards of Pennsylvania," Journal of Economic Entomology, vol. 76, pp. 577-583, 1983.

[25] M. W. Brown and B. D. Short, "Factors affecting appearance of stink bug (Hemiptera: Pentatomidae) injury on apple," Environmental Entomology, vol. 39, no. 1, pp. 134-139, 2010.

[26] K. Funayama, "Importance of apple fruits as food for the brown-marmorated stink bug, Halyomorpha halys (Stål) (Heteroptera: Pentatomidae)," Applied Entomology and Zoology, vol. 39, no. 4, pp. 617-623, 2004.

[27] T. C. Leskey, B. D. Short, S. E. Wright, and M. W. Brown, "Diagnosis and variation in appearance of brown stink bug (Hemiptera: Pentatomidae) injury on apple," Journal of Entomological Science, vol. 44, no. 4, pp. 314-322, 2009.

[28] M. W. Brown, S. S. Miller, and K. S. Yoder, "Stink bug (Pentatomidae) feeding preferences among apple cultivars," Journal of the American Pomological Society, vol. 60, no. 3, pp. 144-148, 2006.

[29] P. G. Tillman, "Influence of corn on stink bugs (Heteroptera: Pentatomidae) in subsequent crops," Environmental Entomology, vol. 40, pp. 1159-1176, 2011.

[30] P. G. Tillman, T. D. Northfield, R. F. Mizell, and T. C. Riddle, "Spatiotemporal patterns and dispersal of stink bugs (Heteroptera: Pentatomidae) in peanut-cotton farmscapes," Environmental Entomology, vol. 38, no. 4, pp. 1038-1052, 2009.

[31] W. G. Foshee, R. T. Boozer, E. K. Blythe, D. L. Horton, and J. Burkett, "Management of plum curculio and catfacing insects on peaches in central Alabama: standard crop stage-based vs. 
Integrated pest management-based approaches," International Journal of Fruit Science, vol. 8, no. 3, pp. 188-199, 2008.

[32] D. Horton, P. Brannen, B. Bellinger, D. Lockwood, and D. Ritchie, Southeastern Peach, Nectarine and Plum Pest Management and Culture Guide, 2011.

[33] A. L. Nielsen, G. C. Hamilton, and D. Matadha, "Developmental rate estimation and life table analysis for Halyomorpha halys (Hemiptera: Pentatomidae)," Environmental Entomology, vol. 37, no. 2, pp. 348-355, 2008.

[34] S. V. Joseph, J. C. Bergh, S. E. Wright, and T. C. Leskey, "Factors affecting captures of brown marmorated stink bug. Halyomorpha halys (Heteroptera: Pentatomidae) in baited pyramid traps," Journal of Entomological Science. In press.

[35] K. Funayama, "Seasonal fluctuations and physiological status of Halyomorpha halys (Stål) (Heteroptera: Pentatomidae) adults captured in traps baited with synthetic aggregation pheromone of Plautia crossota stali Scott (Heteroptera: Pentatomidae)," Japanese Journal of Applied Entomology and Zoology, vol. 52, no. 2, pp. 69-75, 2008.

[36] P. G. Tillman, J. R. Aldrich, A. Khrimian, and T. E. Cottrell, "Pheromone attraction and cross-attraction of Nezara, Acrosternum, and Euschistus spp. Stink bugs (Heteroptera: Pentatomidae) in the field," Environmental Entomology, vol. 39, no. 2, pp. 610-617, 2010. 

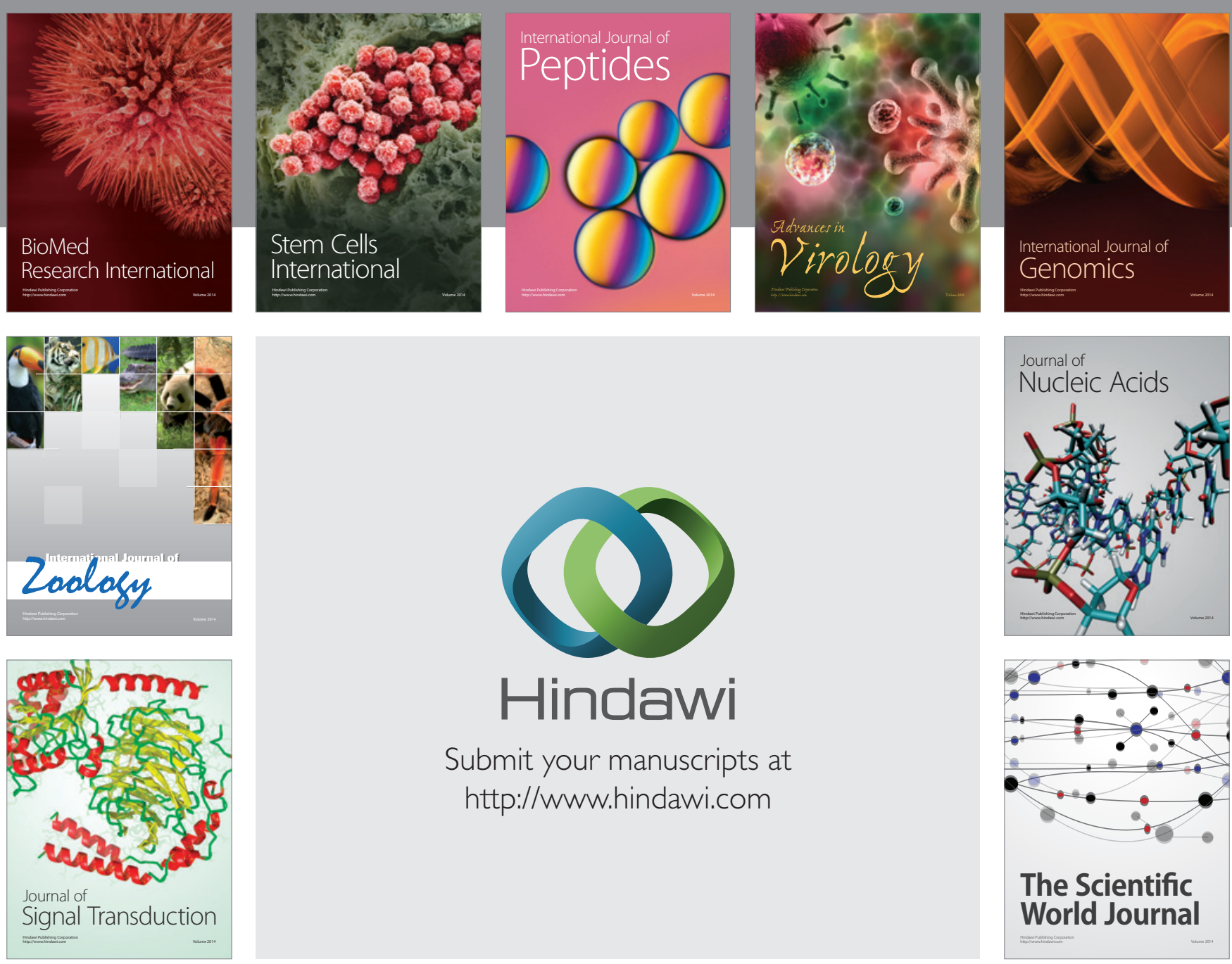

Submit your manuscripts at

http://www.hindawi.com
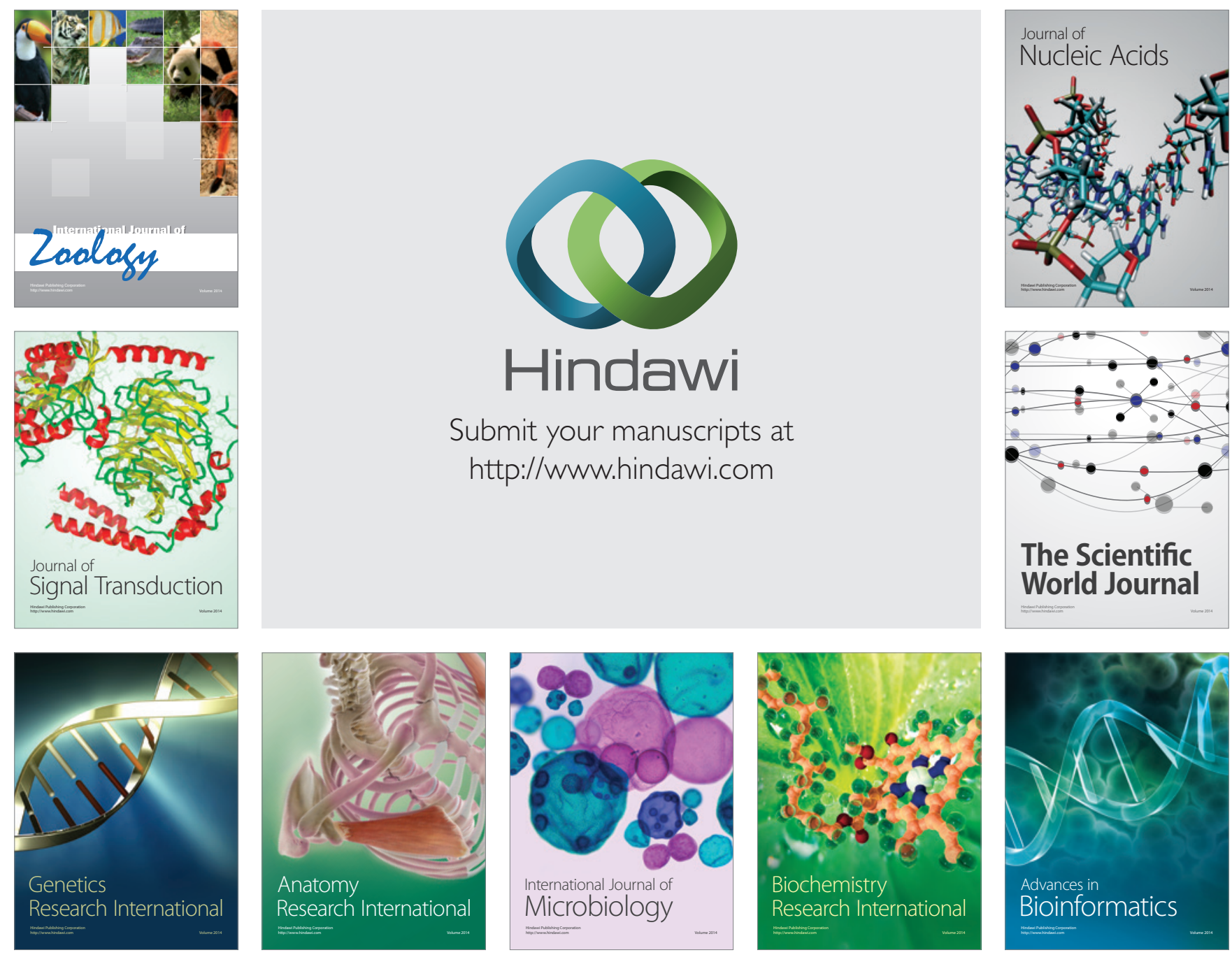

The Scientific World Journal
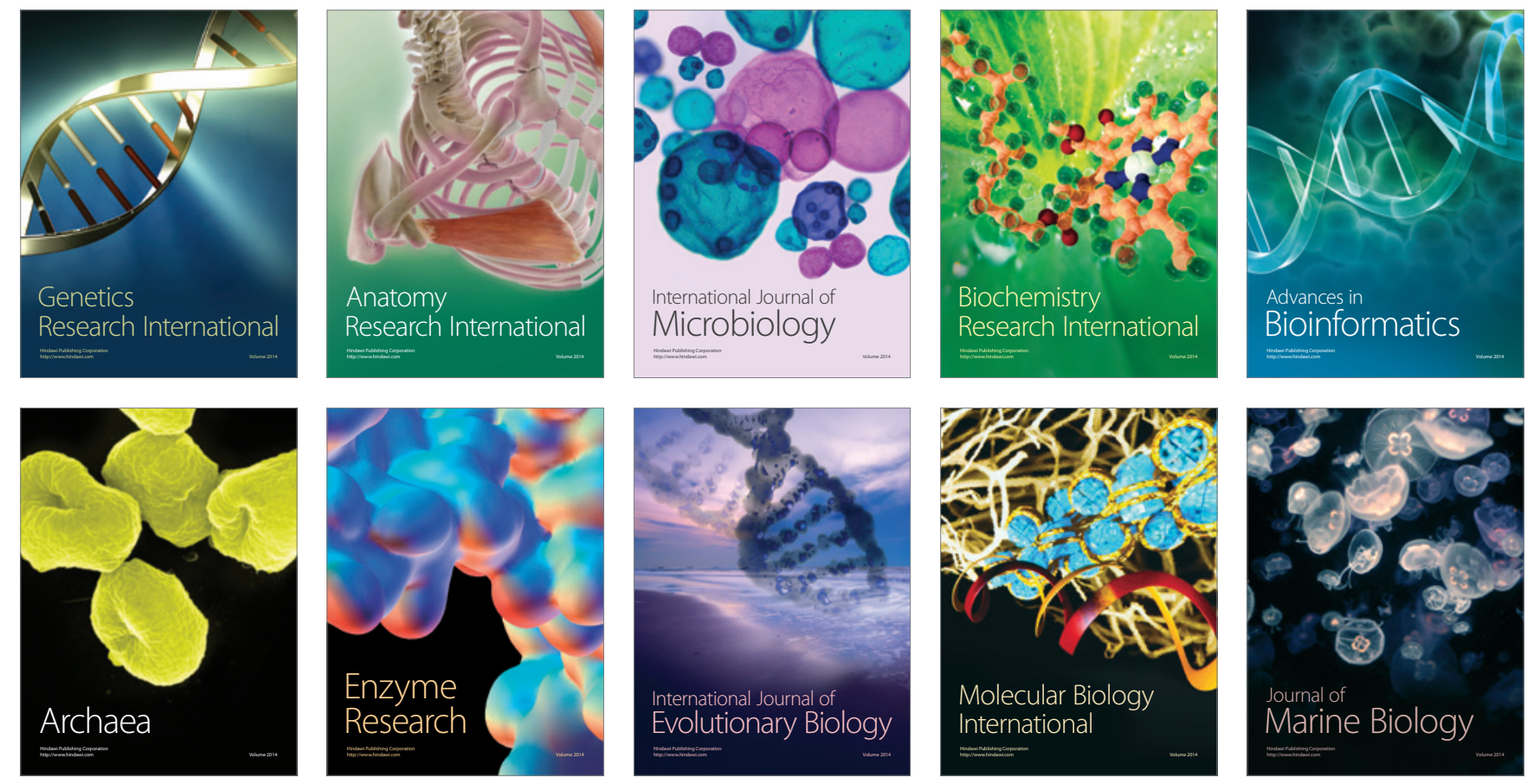